\title{
An Empirical Evaluation of the Global Deterioration Scale for Staging Alzheimer's Disease
}

\author{
Carl Eisdorfer, Ph.D., M.D., Donna Cohen, Ph.D., Gregory J. Paveza, Ph.D., \\ J. Wesson Ashford, M.D., Ph.D., Daniel J. Luchins, M.D., Ph.D., \\ Philip B. Gorelick, M.D., M.P.H., Robert S. Hirschman, Ph.D., \\ Sally A. Freels, Ph.D., Paul S. Levy, Sc.D., \\ Todd P. Semla, M.S., Pharm.D., and Helen A. Shaw, M.A.
}

Obiective; Although the Global Deterioration Scale has been widely used since its publication in 1982, its stages are based on implicit assumptions about the linearity, temporality, and interdependence of cognitive, functional, and behavioral impairment in Alzheimer's disease. The authors evaluated the validity of these assumptions and tested the hypothesis that psychopathology and functional impairment would occur in earlier stages than the Global Deterioration Scale predicts. Method: The analyses were based on data on 324 patients with Alzheimer's disease who were selected from a registry of such patients. Data analyses included 1) descriptive statistics on the frequency of psychiatric symptoms and difficulties with activities of daily living and 2) logistic regression, with symptoms and functional impairment as independent variables, to test for significant changes in patients' status between stages of the Global Deterioration Scale. Results: More than 50\% of the patients at stage 2 displayed psychopathology, and $32 \%$ had two or more symptoms. The significant increase in psychiatric symptoms occurred between stages 3 and 4, not between stages 5 and 6 as predicted by the Global Deterioration Scale. Impairment in functional status was observed at all stages, and significant increases occurred between stages 3 and 4 as well as between stages 5 and 6. Conclusions: Psychiatric symptoms and functional impairment occur earlier than predicted by the Global Deterioration Scale, and the rate of change is also different from that specified in the scale. Separate scales to describe cognitive, clinical, and functional status may be the best way to describe the illness until better multidimensional instruments are developed.

(Am J Psychiatry 1992; 149:190-194)

\begin{abstract}
A lzheimer's disease has been described as an unrelenting "loss of self" (1) characterized by progressive decline of cognitive and functional capacities as well as psychiatric morbidity (DSM-III-R, 2). The disease manifests itself in multiple ways, and there is considerable value in developing a scale to describe patients' status. However, limited data are available to document the incidence and prevalence of changes during the course of illness ( 3 , and unpublished work of D.

Received March 5, 1991; revision received July 17, 1991; accepted Aug. 16, 1991. From the Department of Psychiatry, University of Miami; the School of Public Health and the College of Pharmacy, University of Illinois at Chicago; the Department of Psychiatry, University of Chicago; and the Department of Psychiatry, University of Wiscon$\sin$ (Milwaukee campus). Address reprint requests to Dr. Eisdorfer, Department of Psychiatry (D-28), University of Miami School of Medicine, P.O. Box 016960, Miami, FL 33101.

Supported in part by grant AG-06777 to Dr. Cohen from the National Institute on Aging.

Copyright $\odot 1992$ American Psychiatric Association.
\end{abstract}

Cohen et al.), and significant variability has been reported in the rate of change in cognitive and noncognitive dysfunction (4-6). Such information is fundamental for the construction of accurate scales for global staging of Alzheimer's disease.

While a number of scales exist, one of the most widely used instruments to stage the course of Alzheimer's disease is the Global Deterioration Scale (7) for primary degenerative dementia. The Global Deterioration Scale is a seven-stage rating scale in which stage 1 reflects no cognitive decline, stage 2 reflects very mild cognitive decline, and stages 3-7 are defined, respectively, as mild, moderate, moderately severe, severe, and very severe cognitive decline. Each stage is associated with clinical phases ranging from normal (stage 1) to late dementia (stage 7), and each is also accompanied by a brief description of clinical characteristics (i.e., functional status, behavioral functioning, psychiatric problems) presumably associated with each stage. Finally, each stage has a diagnostic label: "normal" and "normal aged" for stages 1 and 2, "com- 
EISDORFER, COHEN, PAVEZA, ET AL.

patible with incipient Alzheimer's disease" for stage 3, and "mild Alzheimer's disease" to "severe Alzheimer's disease" for stages 4-7.

The Global Deterioration Scale has played an important role in clinical care by focusing attention on the level of patient decline, but the scale itself has significant conceptual and methodological limitations. Reisberg et al. (8) reported that the scale was developed using what they described as "systematic phenomenologic observation" of the nature of symptoms in patients with Alzheimer's disease as well as in other individuals with age-associated memory impairment. There was no clear discussion of the psychometric methods used to relate the seven stages to the clinical parameters specified in the scale. Furthermore, the clinical description for each stage uses different units of observations for behavioral dysfunction. The Global Deterioration Scale is based on implicit assumptions about the linearity, temporality, and interdependencies of cognitive, functional, and behavioral impairment as well as neuroanatomical integrity. These assumptions require empirical evidence to support the Global Deterioration Scale's descriptions of incidence and changes in behavioral dysfunction across the seven stages.

The development of the Global Deterioration Scale relied heavily on correlations between progression on the scale and brain imaging data in a sample of $43 \mathrm{pa}$ tients and seven other persons who underwent positron emission tomography (PET) scans of their brains $(7,8)$. In addition, Global Deterioration Scale scores were correlated with several cognitive domains and functional abilities derived from tests with 54 patients and from interviews with 36 patients concerning adaptation.

The Global Deterioration Scale makes predictions about patients' ability to function, as reflected in activities of daily living (e.g., bathing, dressing) and instrumental activities of daily living (e.g., handling money, using a telephone), as well as psychiatric morbidity, on the basis of progressive cognitive loss. In general, the scale postulates that significant functional and psychiatric disability does not occur until the latter stages of dementia. It specifies that psychiatric symptoms such as flattening of affect and anxiety occur in stage 4 and that it is not until stage 6 that pervasive personality and emotional changes occur. Progression of functional impairments is described in the Global Deterioration Scale with uneven detail, but stage 6 is described as the period when some assistance is needed with activities of daily living. The scale states that no assistance with toileting is needed in stage 5 but that patients will have difficulty choosing clothes. In the final stage, patients are described as incontinent of urine, needing assistance with toileting and eating, and losing the ability to walk.

The empirical literature on Alzheimer's disease as well as consensus diagnostic criteria for the disease suggest that psychopathology and functional impairment are prevalent conditions (DSM-III-R, 2, 3, 6, and unpublished work of D. Cohen et al.). Therefore, we hypothesized that psychopathology and functional impairment would occur in patients at all stages of the Global Dete-
TABLE 1. Ranges of Scores on the Mini-Mental State Examination Used in This Study to Assign Patients With Alzheimer's Disease to Global Deterioration Scale Stages 2-7 and Ranges Used by Reisberg et al. (11)

\begin{tabular}{lcc}
\hline \multirow{2}{*}{$\begin{array}{l}\text { Rtage on Global } \\
\text { Deterioration Scale }\end{array}$} & \multicolumn{2}{c}{ Range of Scores on Mini-Mental State } \\
\cline { 2 - 3 } & Reisberg et al. Study & This Study \\
\hline 2 & $25-30$ & $26-30$ \\
3 & $20-27$ & $21-25$ \\
4 & $16-23$ & $17-20$ \\
5 & $10-19$ & $11-16$ \\
6 & $0-12$ & $1-10$ \\
7 & 0 & 0 \\
\hline
\end{tabular}

rioration Scale and that significant differences in adjacent stages would occur before the transition from stage 5 to stage 6 as predicted by Reisberg et al. (7).

\section{METHOD}

We used a set of data from a registry of patients with Alzheimer's disease to evaluate the Global Deterioration Scale in a large sample. The data include sociodemographic, clinical, and psychosocial information on dementia patients enrolled at six medical centers in three states between May 1988 and May 1989 (9). The clinical centers enrolled patients 40 years of age or older who were living in the community and who had been diagnosed as having Alzheimer's disease or a related disorder between 1987 and 1989. The Alzheimer's disease patient registry, also known as the Prototype Alzheimer Collaborative Team, was funded as part of a cooperative agreement by the National Institutes of Health and the National Institute on Aging to test the feasibility of enrolling large numbers of patients with dementia at diverse clinical sites in a registry for research on Alzheimer's disease.

The case registration and data collection methods as well as a sociodemographic profile of the entire Prototype Alzheimer Collaborative Team population have been described elsewhere (9). Briefly, a central Data Coordinating and Analysis Center in the School of Public Health at the University of Illinois at Chicago registered patients with Alzheimer's disease and related disorders enrolled at six medical sites in the Miami, Milwaukee, and Chicago areas. The sample for this study included 324 of these patients. Three hundred twenty of them met the DSM-III-R or NINCDS-ADRDA (2) criteria for Alzheimer's disease, and an additional four patients were given the diagnosis of primary degenerative dementia according to DSM-III. Subjects included in this analysis also had to have no missing data for sociodemographic, psychiatric, mental status, and functional status variables recorded in the case enrollment forms.

Two procedural decisions were made prior to the data analyses for this report. First, we established ranges of nonoverlapping scores on the Mini-Mental State examination (10) as the criteria for defining the seven stages. These ranges, identified in table 1 , were modified from 
TABLE 2. Characteristics of 324 Patients With Alzheimer's Disease Classified According to Stages on the Global Deterioration Scale

\begin{tabular}{|c|c|c|c|c|c|c|}
\hline \multirow{2}{*}{$\begin{array}{l}\text { Stage on } \\
\text { Global } \\
\text { Deterioration } \\
\text { Scale }\end{array}$} & \multirow[b]{2}{*}{$\mathbf{N}$} & \multicolumn{2}{|c|}{ Age (years) } & \multirow{2}{*}{$\begin{array}{l}\text { Sex } \\
\text { Ratio } \\
\text { (M/F) }\end{array}$} & \multicolumn{2}{|c|}{$\begin{array}{c}\text { Duration } \\
\text { of Illness } \\
\text { (years) }^{\mathbf{a}}\end{array}$} \\
\hline & & Mean & SD & & Mean & SD \\
\hline 2 & 25 & 72.4 & 8.7 & 1.5 & 1.9 & 1.2 \\
\hline 3 & 66 & 73.2 & 7.8 & 0.7 & 3.6 & 3.6 \\
\hline 4 & 68 & 74.1 & 7.6 & 0.5 & 3.4 & 3.0 \\
\hline 5 & 79 & 76.6 & 7.8 & 0.5 & 3.7 & 2.7 \\
\hline 6 & 70 & 75.3 & 6.9 & 0.5 & 4.4 & 2.4 \\
\hline 7 & 16 & 72.8 & 8.6 & 0.7 & 5.4 & 2.0 \\
\hline Total & 324 & 74.6 & 7.8 & 0.5 & 3.7 & 2.9 \\
\hline
\end{tabular}

${ }^{2}$ Duration of illness was extracted from the case enrollment form. It indicates time from onset of first symptoms, with documentation of the types of symptoms (e.g., memory, language) and time of diagnosis.

the overlapping ranges of the Global Deterioration Scale published in 1986 (11). Although Reisberg et al. (11) have argued that mental status scores are not the sole criteria for assignment to the stages of the Global Deterioration Scale, they defined these stages in cognitive terms $(7,8$, 11). It was necessary to eliminate overlapping scores to establish the frequency distributions of the noncognitive variables. Second, we chose to examine stages of the Global Deterioration Scale only among Prototype Alzheimer Collaborative Team registry cases in which the patients met diagnostic criteria for probable or possible Alzheimer's disease according to the NINCDS/ADRDA criteria (2), primary degenerative dementia of the Alzheimer type according to DSM-III-R, or primary degenerative dementia according to DSM-III. Table 2 presents characteristics of the sample classified into stages 2-7, since stage 1 refers to no cognitive decline.

Data analysis consisted of 1) descriptive statistics on the frequency of occurrence of psychiatric morbidity and impairment in the six activities of daily living rated in the Prototype Alzheimer Collaborative Team cases and 2) logistic regression (12), with individual psychiatric symptoms and functional impairment as independent variables, to test for significant changes between stages of the Global Deterioration Scale. For each symptom or impairment category, logistic regression was used to test differences in prevalence between adjacent pairs of stages. If onset of a given symptom is associated with stage $k$, then the prevalence of that symptom at stage $k$ should be significantly higher than at stage $k-1$. The differences between adjacent stages 2 through 7 were coded as five indicator variables: $X_{3}$ was 1 if the stage was 3 or more and 0 if it was otherwise, $X_{4}$ was 1 if the stage was 4 or more and 0 if it was otherwise, and so on up to $\mathrm{X}_{7}$, which was 1 if the stage was 7 and 0 if it was otherwise. With these five indicator variables as predictors and the logit of symptom or functional impairment status as the outcome, the coefficient beta $a_{k}$ for $X_{k}$ is equal to the log odds of prevalence in stage $k$ versus prevalence in stage $k-1$. If beta $k=0$, then the preva-
TABLE 3. Prevalence of Psychiatric Symptoms in 324 Patients With Alzheimer's Disease Classified According to Stages on the Global Deterioration Scale

\begin{tabular}{|c|c|c|c|c|c|c|c|}
\hline \multirow{2}{*}{$\begin{array}{l}\text { Stage on } \\
\text { Global } \\
\text { Deterioration } \\
\text { Scale }\end{array}$} & \multirow[b]{2}{*}{$\mathbf{N}$} & \multicolumn{2}{|c|}{$\begin{array}{l}\text { Patients } \\
\text { With at } \\
\text { Least One } \\
\text { Symptom }\end{array}$} & \multicolumn{2}{|c|}{$\begin{array}{l}\text { Patients } \\
\text { With } \\
\text { One } \\
\text { Symptom }\end{array}$} & \multicolumn{2}{|c|}{$\begin{array}{l}\text { Patients } \\
\text { With Two } \\
\text { or More } \\
\text { Symptoms }\end{array}$} \\
\hline & & $\mathrm{N}$ & $\%$ & $\mathrm{~N}$ & $\%$ & $\mathbf{N}$ & $\%$ \\
\hline 2 & 25 & 13 & 52.0 & 5 & 20.0 & 8 & 32.0 \\
\hline 3 & 66 & 36 & $54.5^{\mathrm{a}}$ & 20 & 30.3 & 16 & $24.2^{b}$ \\
\hline 4 & 68 & 48 & $70.6^{a}$ & 11 & 16.2 & 37 & $54.4^{b}$ \\
\hline 5 & 79 & 60 & 75.9 & 15 & 19.0 & 45 & 56.9 \\
\hline 6 & 70 & 54 & 77.1 & 8 & 11.4 & 46 & 65.7 \\
\hline 7 & 16 & 14 & 87.5 & 2 & 12.5 & 12 & 75.0 \\
\hline
\end{tabular}

${ }^{a}$ Significant difference between stage 3 and stage $4\left(\chi^{2}=4.18, \mathrm{df}=1\right.$, $\mathrm{p}=0.04$ ).

${ }^{b}$ Significant difference between stage 3 and stage $4\left(\chi^{2}=12.15, d f=2\right.$, $\mathrm{p}=0.002$ ).

lence in stage $\mathrm{k}$ is equal to the prevalence in stage $\mathrm{k}-1$. The null hypothesis, beta $a_{k}=0$, was tested for each coefficient in each model by a chi-square test with one degree of freedom.

\section{RESULTS}

As shown in table 3, 52.0\% of the Alzheimer's disease patients at stage 2 displayed psychopathology, and $32.0 \%$ had two or more symptoms. By stage $6,77.1 \%$ had psychiatric morbidity, but the significant increase between adjacent levels occurred earlier than postulated by the Global Deterioration Scale, i.e., between stages 3 and 4 , not stages 5 and 6 .

The results of logistic regression procedures to test significant differences in the prevalence of nine psychiatric symptoms by Global Deterioration Scale stage are reported in table 4. Although patients at all stages displayed agitation, a statistically significant increase in agitation occurred between stages 3 and 4 . The prevalence of hallucinations and insomnia also increased significantly between stages 3 and 4 .

Impairment in activities of daily living was observed in patients at all stages of the Global Deterioration Scale. Although functional impairments were more severe in later stages, $20 \%$ of the patients in stage 2 had at least one impairment in activities of daily living. This doubled to $40 \%$ for patients in stage 3 and continued to increase to $51 \%$ for those in stage $4,65 \%$ in stage $5,77 \%$ in stage 6 , and $100 \%$ in stage 7 . As shown in table 5 , the percentage of patients with difficulties in bathing changed significantly from stage 3 to stage 4 and from stage 5 to stage 6 . The most significant change in difficulties in dressing on adjacent stages of the Global Deterioration Scale occurred between stages 4 and 5; however, fully one-fifth of the patients were impaired on this variable in stage 3 . The most significant shifts for eating, transferring from bed to chair, and walking occurred between stages 5 and 6 and stages 6 and 7. 
EISDORFER, COHEN, PAVEZA, ET AL.

TABLE 4. Prevalence of Psychiatric Symptoms in 324 Patients With Alzheimer's Disease Classified According to Stages on the Global Deterioration Scale

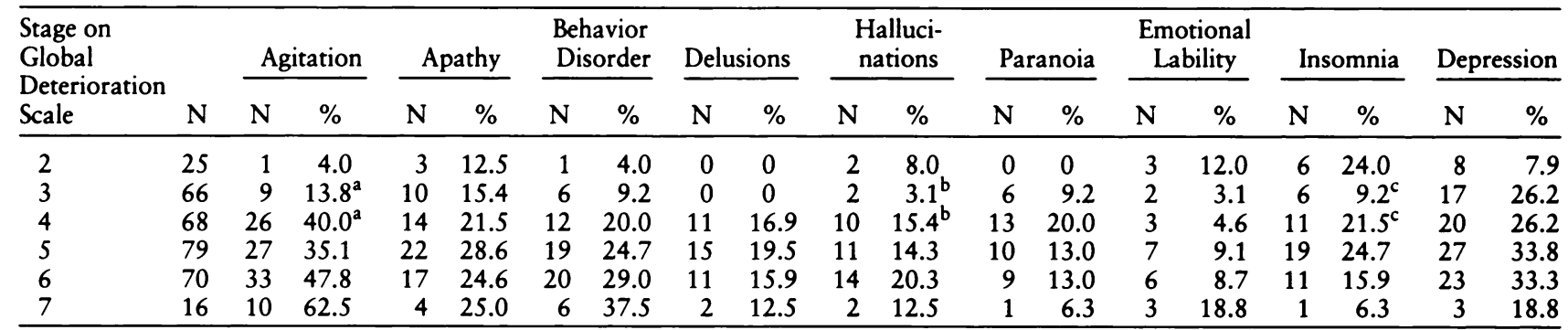

${ }^{a}$ Significant difference between stage 3 and stage 4 (beta $=1.37 ; \chi^{2}=9.78, \mathrm{df}=1, \mathrm{p}=0.002$ ).

bignificant difference between stage 3 and stage 4 (beta $=1.71 ; \chi^{2}=4.61, \mathrm{df}=1, \mathrm{p}=0.03$ ).

'Significant difference between stage 3 and stage 4 (beta $=1.04 ; \chi^{2}=4.03, \mathrm{df}=1, \mathrm{p}=0.04$ ).

TABLE 5. Prevalence of Impairments in Activities of Daily Living in 324 Patients With Alzheimer's Disease Classified According to Stages on the Global Deterioration Scale

\begin{tabular}{|c|c|c|c|c|c|c|c|c|c|c|c|c|c|}
\hline \multirow{2}{*}{$\begin{array}{l}\text { Stage on Global } \\
\text { Deterioration } \\
\text { Scale }\end{array}$} & \multirow[b]{2}{*}{$\mathrm{N}$} & \multicolumn{2}{|c|}{ Bathing } & \multicolumn{2}{|c|}{ Dressing } & \multicolumn{2}{|c|}{ Eating } & \multicolumn{2}{|c|}{ Transfering } & \multicolumn{2}{|c|}{ Walking } & \multicolumn{2}{|c|}{ Toileting } \\
\hline & & $\mathrm{N}$ & $\%$ & $\mathrm{~N}$ & $\%$ & $\mathrm{~N}$ & $\%$ & $\mathbf{N}$ & $\%$ & $N$ & $\%$ & $\mathrm{~N}$ & $\%$ \\
\hline 2 & 25 & 1 & 4.2 & 3 & 12.5 & 0 & 0 & 1 & 4.2 & 0 & 0 & 3 & 12.0 \\
\hline 3 & 66 & 8 & $12.5^{\mathrm{a}}$ & 14 & 20.8 & 3 & 4.8 & 14 & 21.9 & 9 & 13.8 & 8 & 12.5 \\
\hline 4 & 68 & 24 & $35.2^{\mathrm{a}}$ & 21 & $30.5^{\mathrm{b}}$ & 8 & 12.5 & 21 & 31.6 & 8 & 12.1 & 13 & 19.6 \\
\hline 5 & 79 & 31 & $38.8^{\mathrm{c}}$ & 34 & $42.9^{b}$ & 8 & $10.8^{\mathrm{d}}$ & 29 & $37.0^{\mathrm{e}}$ & 15 & $19.2^{\mathrm{f}}$ & 17 & $21.1^{8}$ \\
\hline 6 & 70 & 41 & $58.5^{\mathrm{c}}$ & 39 & 55.9 & 21 & $30.3^{\mathrm{d}, \mathrm{h}}$ & 27 & $39.1^{\mathrm{e}, \mathrm{i}}$ & 19 & $27.1^{f, j}$ & 27 & $38.8^{8}$ \\
\hline 7 & 16 & 13 & 81.3 & 16 & 100.0 & 10 & $60.0^{\mathrm{h}}$ & 12 & $75.0^{\mathrm{i}}$ & 5 & $31.3^{\mathrm{j}}$ & 12 & 73.3 \\
\hline
\end{tabular}

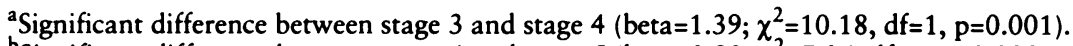

bignificant difference between stage 4 and stage 5 (beta $=0.93 ; \chi^{2}=7.06, \mathrm{df}=1, \mathrm{p}=0.008$ ).

'Significant difference between stage 5 and stage 6 (beta $=0.69 ; \chi^{2}=4.57, \mathrm{df}=1, \mathrm{p}=0.03$ ).

${ }^{\mathrm{d}}$ Significant difference between stage 5 and stage 6 (beta $=1.10 ; \chi^{2}=7.30, \mathrm{df}=1, \mathrm{p}=0.007$ ).

'Significant difference between stage 5 and stage 6 (beta $=0.65 ; \chi^{2}=3.83, \mathrm{df}=1, \mathrm{p}=0.05$ ).

'Significant difference between stage 5 and stage 6 (beta $=0.74 ; \chi^{2}=4.42, \mathrm{df}=1, \mathrm{p}=0.04$ ).

${ }^{8}$ Significant difference between stage 5 and stage 6 (beta $=0.65 ; \chi^{2}=3.89, \mathrm{df}=1, \mathrm{p}=0.05$ ).

${ }^{\mathrm{h}}$ Significant difference between stage 6 and stage 7 (beta $=1.22 ; \chi^{2}=4.38, \mathrm{df}=1, \mathrm{p}=0.04$ ).

'Significant difference between stage 6 and stage 7 (beta $=1.63 ; \chi_{2}^{2}=5.63, \mathrm{df}=1, \mathrm{p}=0.02$ ).

'Significant difference between stage 6 and stage 7 (beta $=1.53 ; \chi^{2}=5.88, \mathrm{df}=1, \mathrm{p}=0.02$ ).

\section{DISCUSSION}

Since its publication in 1982, the Global Deterioration Scale has been widely used to stage Alzheimer's disease. It was developed by using primarily a conceptual approach, rather than psychometric and statistical methods, to describe cognitive and noncognitive characteristics associated with the course of this disease and related disorders. A number of assumptions were made concerning the occurrence, rate of change, and interrelationships of cognitive impairment, behavioral dysfunction, impairment in activities of daily living, and psychiatric symptoms.

Our results show that significant psychopathology occurs at earlier stages of the Global Deterioration Scale than predicted by Reisberg et al. (7). Although the scale specifically states that no assistance with toileting and eating is needed until stage $6,21.1 \%$ of the patients in stage 5 had problems with toileting and $10.8 \%$ had problems with eating. The most significant changes in problems with bathing occurred between stages 3 and 4 as well as between stages 5 and 6 . Bathing is not referred to explicitly in the Global Deterioration Scale, but even if it is classified under the general category of "some assistance with activities of daily living" in stage 6 , significant change occurred earlier than predicted. Although the Global Deterioration Scale specifically states that no assistance is needed for eating and toileting in stage 5 but is needed in stage 7, these results show an earlier shift.

Our results support one of the basic assumptions underlying the Global Deterioration Scale and all other clinical staging instruments, i.e., that patients with $\mathrm{Alz}$ heimer's disease become progressively worse as a natural course of the disease. Indeed, the most useful rating scales for staging Alzheimer's disease rely heavily on cognitive measures (13-15).

It is clear from our results that psychiatric pathology and functional impairment associated with Alzheimer's disease occur sooner than predicted by the Global Deterioration Scale and that the rate of change is different from that specified in the instrument. Our results also have broader implications for understanding Alzheimer's disease. A wide range of psychiatric symptoms may be seen quite early in the disease. Even Alois Alzheimer's initial report (16) described a number of psychiatric symptoms in his 51 -year-old patient, including 
strong feelings of jealousy as the earliest presentation of the disorder. Although cognitive deficits are primary symptoms, they rarely occur without substantial dysfunction in other areas.

The Global Deterioration Scale has been reported to have good interrater reliability, ranging from 0.82 to $0.92(13,17,18)$. Its validity is difficult to evaluate without prospective longitudinal clinical studies with standardized assessments of the cognitive and noncognitive variables, followed by neuropathological confirmation of the diagnosis of Alzheimer's disease. Validation studies reported to date have relied on correlations of assigned stages of the Global Deterioration Scale with clinical, psychometric, and imaging (i.e., CT and PET scan) variables $(7,8,17-19)$. These, however, are indirect measures of validity.

The authors of the Global Deterioration Scale are probably correct in asserting that ordinal progression of functional decline may be affected by coexisting pathology. However, they implicitly postulate a single, relatively consistent progression of decline in Alzheimer's disease without empirically verifying this hypothesis. An example of the difficulties that may occur in the utilization of the scale is the assumption, according to the scale, that symptoms of Alzheimer's disease are not detectable in stage 2 and that stage 3 defines incipient Alzheimer's disease $(7,8,11$, 19). The results in this report demonstrate that patients with clinically diagnosed disease and mild impairment according to the Mini-Mental State examination can be classified in stage 2 , and by that stage they already show significant psychopathology.

The use of the Global Deterioration Scale as a global staging instrument carries with it the subtle hazard that because the scaled score provides information in a quasimathematical form, it can appear to convey more information about the patient's condition than it actually does. In addition, it presumes the homogeneity of Alzheimer's disease, whereas a growing literature supports the hypothesis that it may be a heterogeneous disease (20-24).

Since staging of Alzheimer's disease by using the Global Deterioration Scale implies an overall clinical state, which in turn is a basis for examining other clinical variables, it is important to recognize that these variables array themselves differently than posited in the Global Deterioration Scale. The use of separate instruments to describe cognitive status, psychiatric symptoms, and functional status $(10,14,25)$ may be the most accurate way to describe the illness until better multidimensional scales are developed.

\section{REFERENCES}

1. Cohen D, Eisdorfer C: The Loss of Self. New York, WW Norton, 1986

2. McKhann G, Drachman D, Folstein M, Katzman R, Price D, Stadlan EM: Clinical diagnosis of Alzheimer's disease: report of the NINCDS-ADRDA Work Group under the auspices of the Department of Health and Human Services Task Force on Alzheimer's Disease. Neurology 1986; 34:939-944

3. Wragg RE, Jeste DV: Overview of depression and psychosis in Alzheimer's disease. Am J Psychiatry 1989; 146:577-587
4. Katzman R, Brown T, Thal JL, Fuld PA, Aronson M, Butler N, Klauber MR, Wiederholt W, Pay M, Renbing X, Oui WL, Hofstetter R, Terry RD: Comparison of rate of annual change of mental status in four independent studies of patients with Alzheimer's disease. Ann Neurol 1988; 24:384-389

5. Botwinick J, Storandt M, Berg L: A longitudinal behavioral study of senile dementia of the Alzheimer type. Arch Neurol 1986; 42: 1124-1126

6. Rubin EG, Morris JC, Berg L: The progression of personality changes in senile dementia of the Alzheimer type. J Am Geriatr Soc 1987; 35:721-725

7. Reisberg B, Ferris SH, De Leon MJ, Crook T: The Global Deterioration Scale for assessment of primary degenerative dementia. Am J Psychiatry 1982; 139:1136-1139

8. Reisberg B, Ferris S, De Leon MJ, Crook T: Global Deterioration Scale (GDS). Psychopharmacol Bull 1988; 24:661-663

9. Cohen D, Paveza GJ, Levy PS, Ashford JW, Brody JA, Eisdorfer C, Gorelick PB, Hirschman RS: An Alzheimer's disease patient registry: the Prototype Alzheimer Collaborative Team (PACT). Aging 1990; 2:312-316

10. Folstein MF, Folstein SE, McHugh PR: "Mini-Mental State": a practical method for grading the cognitive state of patients for the clinician. J Psychiatr Res 1975; 12:189-198

11. Reisberg B, Ferris SH, Borenstein J, Sinaiko E, De Leon MJ, Buttinger C: Assessment of presenting symptoms, in Handbook for Clinical Memory Assessment of Older Adults. Edited by Poon LW, Crook T, Davis KL, Eisdorfer C, Gurland BJ, Kasniak AW, Thompson LW. Washington, DC, American Psychological Association, 1986

12. Hasmer D, Lemeshow S: Applied Logistic Regression. New York, John Wiley \& Sons, 1989

13. Gottlieb GL, Gur RE, Gur RC: Reliability of psychiatric scales in patients with dementia of the Alzheimer type. Am J Psychiatry 1988; 145:857-860

14. Rosen WG, Mohs RC, Davis KL: A new rating scale for Alzheimer's disease. Am J Psychiatry 1984; 141:1356-1364

15. Hughes CP, Berg L, Danzinger WL, Coben RL, Martin RL: A new clinical scale for the staging of dementia. Br J Psychiatry 1983; 140:566-572

16. Alzheimer A: Uber eine eigenartige Erkrankung der Hirnrinde. Allgemeine Zeitshrift fur Psychiatrie und Psychisch-Gerichtliche Medizin 1907; 64:146-148

17. Foster JR, Sclan S, Welkowitz J, Boksay I, Seeland I: Psychiatric assessment in medical long-term care facilities: reliability of commonly used rating scales. Int J Geriatr Psychiatry 1988; 3:229-233

18. Reisberg B, Ferris SH, Steinberg G, Schulman E, De Leon MJ, Sinaiko E: Longitudinal study of dementia patients and aged controls, in Special Research Methods for Gerontology. Edited by Lawton MP, Herzog AR. Amityville, NY, Baywood, 1989

19. Reisberg B, Ferris SH, Shulman E, Steinberg G, Buttinger C, Sinaiko E, Borenstein J, De Leon MJ, Cohen J: Longitudinal course of normal aging and progressive dementia of the Alzheimer type: a prospective study of 106 subjects over a 3.6 year mean interval. Prog Neuropsychopharmacol Biol Psychiatry 1986; 10:571-578

20. Cohen D, Eisdorfer C, Walford R: Histocompatibility antigens (HLA) and patterns of cognitive loss in dementia of the Alzheimer type. Neurobiol Aging 1981; 2:277-280

21. Mayeux R, Stern Y, Spanton S: Heterogeneity in dementia of the Alzheimer type: evidence of subgroups. Neurology 1985; 35: 453-461

22. Friedland RP (moderator): Alzheimer's disease: clinical and biological heterogeneity. Ann Intern Med 1988; 109:298-311

23. Knesevich JW, Toro FR, Morris JC, LaBarge E: Aphasia, family history, and the longitudinal course of senile dementia of the Alzheimer type. Psychiatry Res 1985; 14:255-263

24. Folstein MF: Heterogeneity in Alzheimer's disease. Neurobiol Aging 1989; 10:434-435 (discussion, 446-448)

25. Loewenstein DA, Amigo E, Duara R, Guterman A, Hurwitz D, Berkowitz N, Wilkie F, Weinberg G, Black B, Gittleman B, Eisdorfer C: A new scale for the assessment of functional status in Alzheimer's disease and related disorders. J Gerontol 1989; 44: 114-121 